\title{
Pattern of Diabetic Foot Disorder in King Khalid Hospital, Hail, Saudi Arabia (2013)
}

\author{
Prof. Safia Moussa ${ }^{1}$, Dr. Amirah Alshammeri ${ }^{2}$, Waad Fahd Youssef Al-Shammary ${ }^{3}$, \\ Najd Saad Alshammeri ${ }^{4}$, Yasmin Saud Alsugh ${ }^{5}$ \\ ${ }^{1}$ Professor,University of Hail, College of Medicine, Microbiology and Parasitology Department, Hail, Saudi Arabia \\ ${ }^{2}$ Teaching Assistant, University of Hail, College of Medicine, Family Medicine Department, Hail, Saudi Arabia \\ ${ }^{3,4,5}$ Internship Medical Student, University of Hail, College of Medicine, Hail, Saudi Arabia
}

\begin{abstract}
Diabetes is a chronic disease that can lead to complications one of them is diabetic foot. The aim of this study was to identify the prevalence of diabetic foot, associated diseases, pattern of amputation and cost effectiveness. Males were found to have a higher prevalence most of our patients were between 60-70 age group, amputation pattern demonstrated an above the knee amputation region to be the highest and a total cost of 1356100 S.Rwas calculated.
\end{abstract}

Keywords: Pattern of Diabetic Foot disorder, King Khalid Hospital, Hail, Saudi Arabia

\section{Introduction}

Diabetes is a chronic disease that can lead to complications one of them is diabetic foot. The development of diabetic foot ulcers usually results from peripheral neuropathy and defective vascularity. The clinical presentation of Diabetic foot (DF) is variable and diabetic foot problems such as ulcerations, infections and gangrene are causes of mortality and they are often healed.

In Saudi Arabia, to treat such a problems we need routine ulcer cares, treatment of infections, amputations, and hospitalizations, which costs billions of Riyals every year and places a tremendous burden on the health care system.

To our knowledge and being one of the new universities, few researches were done on diabetes mellitus with no researches on DF. So, the aim of the present study was to identify the prevalence of diabetic foot, associated diseases, pattern of amputation and cost effectiveness among King Khalid Hospital (KKH) patients in Hail region, Saudi Arabia during year of 2013.

\section{Material and Method}

This study is a retrospective study including 840 Diabetic foot DF patients who have been already diagnosed from 2765 diabetic cases with a percentage of $(30.3 \%)$ from all diabetic case. Files from Diabetes Department, KKH were studied and analysed during the year of 2013. The sociodemographic data, associated disease, and pattern of amputation were collected from the files of the patients. The cost was obtained also from the financial section .It was signed and approved by KKH director.

\begin{tabular}{|c|c|c|}
\hline \multirow{2}{*}{ Age } & \multicolumn{2}{|c|}{ Number and percentages of patients with DF } \\
\cline { 2 - 3 } & No. & $\%$ \\
\hline $20-<40$ & 35 & $4.2 \%$ \\
\hline $40-<60$ & 233 & $27,7 \%$ \\
\hline $60-<80$ & 529 & $63.1 \%$ \\
\hline$>80$ & 43 & $5.1 \%$ \\
\hline Total & 840 & $100 \%$ \\
\hline
\end{tabular}

\section{Results}

Table 1: Gender distribution among patients with diabetic foot in King Khalid Hospital, Hail region, Saudi Arabia;

\begin{tabular}{|c|c|c|}
\hline \multirow{2}{*}{ Gender } & \multicolumn{2}{|c|}{ Total number of patients having DF } \\
\cline { 2 - 3 } & No. & $\%$ \\
\hline Males & 484 & $58 \%$ \\
\hline Females & 356 & $42 \%$ \\
\hline Total & 840 & $100 \%$ \\
\hline
\end{tabular}

\section{Gender distribution in relation to DF}

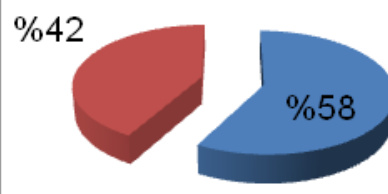

Males

Females

Table 2: Age distribution among patients with diabetic foot in King Khalid Hospital, Hail region, Saudi Arabia:

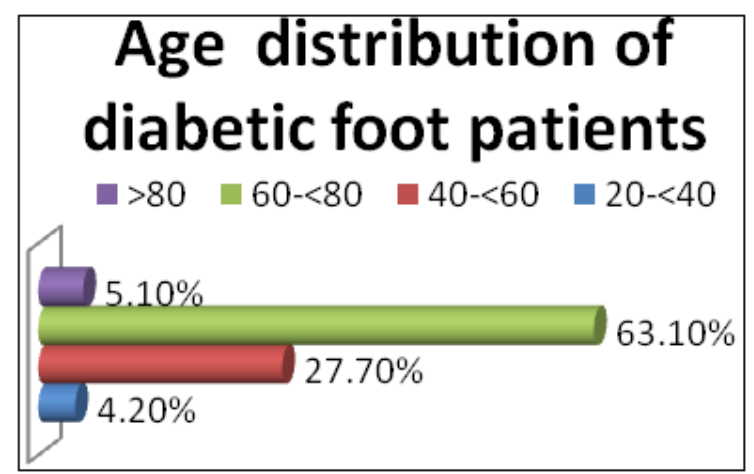

Table 3: Associated disease with diabetic foot among patients with diabetic foot in King Khalid Hospital, Hail region, Saudi Arabia: 


\begin{tabular}{|c|c|c|}
\hline \multirow{2}{*}{ Associated diseases } & \multicolumn{2}{|c|}{$\begin{array}{c}\text { umber and percentages } \\
\text { Of patients with DF }\end{array}$} \\
\cline { 2 - 3 } & No. & $\%$ \\
\hline Hypertension & 410 & $48.8 \%$ \\
\hline Renal disease & 198 & $23.6 \%$ \\
\hline Cardiac diseases & 318 & $37.9 \%$ \\
\hline Renal \&hypertension & 321 & $38.2 \%$ \\
\hline Renal \& cardiac & 236 & $28.1 \%$ \\
\hline Hypertension \& cardiac & 219 & 26.1 \\
\hline Hypertension, Cardiac \& Renal diseases & 89 & 10.6 \\
\hline
\end{tabular}

Total number of patients with diabetic foot: 840

\section{Associated disease with diabetic foot patients}

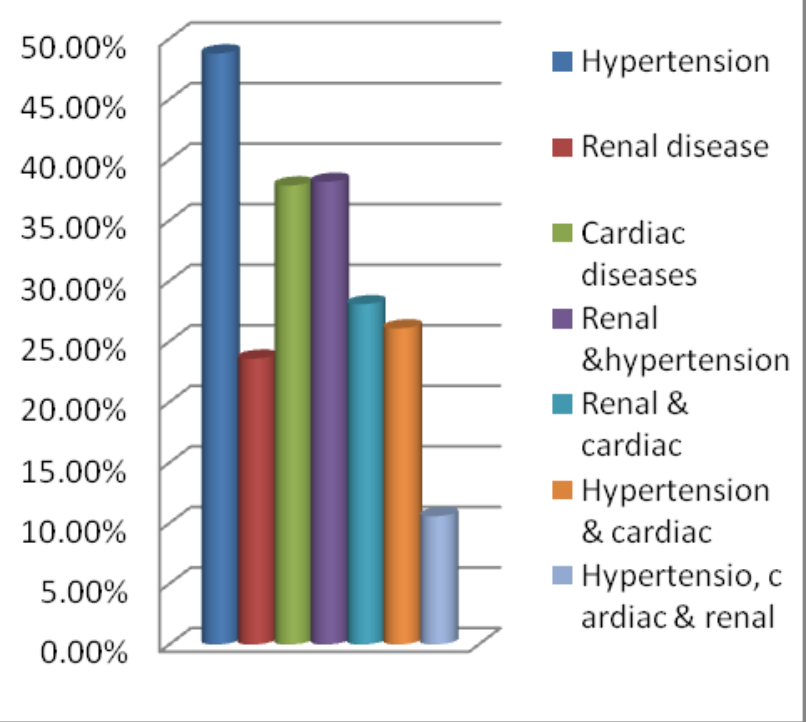

Table 4: Pattern and Classifications of Amputation in diabetic foot patients

Among patients with diabetic foot in King Khalid Hospital, Hail region, Saudi Arabia:

\begin{tabular}{|c|c|c|}
\hline \multirow[t]{2}{*}{ Amputation } & \multicolumn{2}{|c|}{$\begin{array}{c}\text { Number and percentages of patients having } \\
\text { amputation }\end{array}$} \\
\hline & No. & $\%$ \\
\hline Above knee & 8 & $47 \%$ \\
\hline Below knee & 2 & $11.7 \%$ \\
\hline Finger & 1 & $5.8 \%$ \\
\hline Toes & 6 & $35.5 \%$ \\
\hline Total & 17 & $100 \%$ \\
\hline
\end{tabular}

Total number of amputated cases: 17

\section{Levels of amputation}

Aboveknee Below knee Finger $\square$ Toes

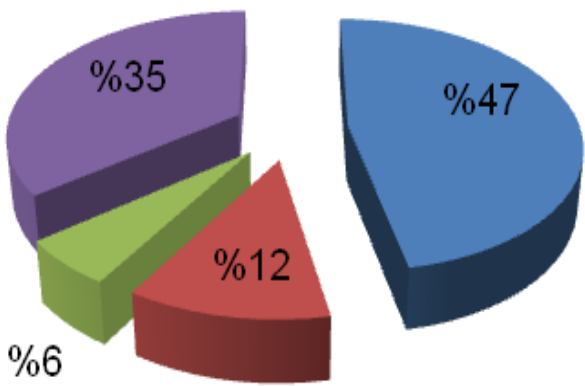

Table 5: Cost effectiveness of among patients with diabetic foot in King Khalid hospital, Hail region, Saudi Arabia

\begin{tabular}{|c|c|c|c|}
\hline Procedure & $\begin{array}{c}\text { Number } \\
\text { of patients }\end{array}$ & $\begin{array}{c}\text { Cost per } \\
\text { procedure/SR }\end{array}$ & $\begin{array}{c}\text { Total costs } \\
\text { /SR }\end{array}$ \\
\hline $\begin{array}{l}\text { Dressing and } \\
\text { Debridement }\end{array}$ & 525 & 196 & 102,900 \\
\hline Stent & 170 & 7,000 & $1,190.000$ \\
\hline $\begin{array}{l}\text { Above knee } \\
\text { amputation } \\
\text { procedure }\end{array}$ & 9 & 4700 & 42,300 \\
\hline $\begin{array}{c}\text { Below knee and } \\
\text { above ankle } \\
\text { amputation } \\
\text { procedure }\end{array}$ & 12 & 4400 & 52,800 \\
\hline $\begin{array}{l}\text { Below ankle } \\
\text { Amputation }\end{array}$ & 11 & 2400 & 26,400 \\
\hline Toe amputation & 15 & 2400 & 36,000 \\
\hline Total & 717 & -- & $1,448,000$ \\
\hline
\end{tabular}

Total number of amputated cases: 47

The results of the present study revealed that were found to have type II diabetes Males (58\%) were commonly affected by diabetic foot than females and most of them were within. the range of $60-<80$ year with average age of $+/-62$ years. hypertension was mainly associated with cases having DF $(48.8 \%) .17(2 \%)$ of the cases had undergone amputation operations. 0,95\% and Patients with above knee amputation represents the majority of total amputated cases $(0,95 \%)$. The total diabetic foot care cost was 1, 448,000 S.R.

\section{Discussion}

In the present study the prevalence of DF among type-II diabetic cases attended to the Diabetes department, was $(30.3 \%)$. It is higher than that reported in Jeddah (Alzahrani et al; 2014). This difference could be explained on the basis that the better health care service and education which give the patients better diabetic control. Males with DF in the current work represented a higher ratio than females $(58 \%)$, which is near to that obtained from a study done in Riyadh $(62.5 \%)$ (Sulimani et al, 1991).

Age distribution among our patients revealed that the most common age group affected was those of $\mathbf{6 0}-<\mathbf{8 0}$ years $(63.1 \%)$ which is near the figure obtained from Riyadh (age average 58) (Sulimani et al, 1991). . However, the average age affected by DF was lower (53\%) in United Arabs of Emirates (Al-Maskari and El-Sadig M; 2007, Sulimani et al, 


\section{International Journal of Science and Research (IJSR) \\ ISSN (Online): 2319-7064 \\ Index Copernicus Value (2013): 6.14 | Impact Factor (2014): 5.611}

1991). The high prevalence of DF among these advanced age group may be due to poor glycaemic and lipid control, associated diseases, poor foot care in elderlies and bad choice of footwear. (Al-Khaldi; 2008)

In the current study, the most prevalent diseases associated with DF were the hypertension (48.8\%). Other study revealed the combination of cardiac diseases with hypertension was the most common among their patients (Alzahrani et al; 2014), The associated diseases reported in the present study were similar to those recorded in that of Jeddah which are hypertension, cardiac disease and renal which are correlate with result found in Jeddah. This further confirms that associated diseases could be risk factor for DF. (Abolfotouh et al; 2011)

Unexpectedly, our data suggest that patients who underwent amputation had mainly above knee amputation (47\%). On the other hand, the common amputation was below knee type in patients of Dammam (Elsharawy; 2011). The difference may be due to advanced foot gangrene that usually left untreated in Hail community.

The cost effective of DF care calculated to be a total of (1, 448,000 S.R.) The most costly procedure done was stenting these may be due to the high-prices of the material used in these procedure. A study in England was found, but it was broader and includes a whole country rather than a city, a total DF care cost per year was $(3,398,2200$ S.R) and the most costly was dressing and debridement. (Kerr; 2014)

\section{Conclusion}

The prevalence of DF among type-II diabetic cases attended to the Diabetes department, was (30.3\%). Males were found to have a higher prevalence most of our patients were between 60-70 age group, amputation pattern demonstrated an above the knee amputation region to be the highest and a total cost of 1356100 S.Rwas calculated.

\section{Recommendations}

1) Health education programs about diabetes control and diabetic foot should be held regularly in institutions, universities, schools and hospitals as well

2) Propagation of diabetes control and diabetic foot education programs through Mass media and newspapers

\section{Limitation of the Study}

Although this study, included 840 participants, this sample is not considered enough to represent the whole Hail community, so in the future, it should extend to cover more areas and hospitals of hail region specially those of the remote villages .

\section{References}

[1] Cost of diabetic foot disease to the National Health Service in England. Kerr M1, Rayman G, Jeffcoate WJ. (2014)
[2] Foot care among male diabetics in family practice center, abha, saudi Arabia Al-Khaldi YM. (2008)

[3] Outcome of midfoot amputations in diabetic gangrene. Elsharawy MA. (2011)

[4] Pattern of diabetic foot lesions in Saudi Arabia: Experience from King Khalid University Hospital, Riyadh. Sulimani RA1, Famuyiwa OO, Mekki MO. (1991)

[5] Prevalence of risk factors for diabetic foot complications. Al-Maskari F1, El-Sadig M (2007)

[6] Risk factors of diabetic foot in central Saudi Arabia. Abolfotouh MA1, Alfaifi SA, Al-Gannas AS. (2011)

[7] Risk factors for peripheral artery disease among patients with diabetes in Saudi Arabia.Alzahrani HA1, Wang D2, Bakhotmah BA3, Hu FB4. (2014)

[8] Al Shafaee M.A., Al-Shukaili S., Rizvi S.G., Al Farsi Y., Khan M.A., Ganguly S.S., Afifi M., and Al Adawi S. (2008): Knowledge and perceptions of diabetes in a semi-urban Omani Population. BMC Public Health, $8: 249$

[9] American Diabetes Association (2008): Nutrition Recommendations and Interventions for Diabetes. Diabetes Care, 31(1) : S61-S78, 2008.

[10] American Diabetes Association (2011): Standards of Medical Care in Diabetes. Diabetes Care, (34)1:S11S61.

[11] Basi S., Fesler P., Mimran A., Lewis J.B. (2008): Microalbuminuria in Type 2 Diabetes and Hypertension. Diabetes Care, 31(2):S194-S201.

[12] Hashmi N.R., Manzoor I., Daud S. (2008 ): Diabetes Mellitus; Awareness Among Individuals Attending Out Patient Department Of Ghurki Trust Teaching Hospital. Professional Med J; 15(1): 96-100.

[13] International Diabetes Federation (2009): SelfMonitoring of Blood Glucose in Non-Insulin Treated Type 2 Diabetes.

[14] Sacks DB, Bruns DE, Goldstein DE, Maclaren NK, McDonald JM, Parrott M. (2002): Guidelines and recommendations for laboratory analysis in the diagnosis and management of diabetes mellitus. Clin Chem;48:436-472.

[15] Shaw J.E., Sicree R.A., Zimmet P.Z. (2010): Global estimates of the prevalence of diabetes for 2010 and 2030. Diabetes research and clinical practice 8 (7) :4 14.

[16] Szymborska-Kajanek A, Psurek A, Hese R, Strojek K (2009): Self-monitoring of blood glucose in treatment of type 2 diabetes. Diabetes Res Clin Pract. 86 (1):S49-52. the Case for Early Insulinisation. Supplement to JAPI 59:8-12.

[17] Unnikrishnan I.R., Anjana R.M., and Mohan V. (2011): Importance of Controlling Diabetes Early-The Concept of Metabolic Memory. 